\title{
BMJ Open Assessing the global risk of cardiovascular disease among a group of university students: population-based cross-sectional study in Yaoundé, Cameroon
}

\author{
Jobert Richie Nansseu, ${ }^{\oplus 1,2}$ Felix Assah, ${ }^{1}$ Saint-Just Petnga, ${ }^{3}$ \\ Bibiane Siaheu Kameni, ${ }^{4}$ Hebert Donald Fosso Tene, ${ }^{5}$ Francial Terrenstra Nang, ${ }^{5}$ \\ Dominic Leandry Angong Wouna, ${ }^{5}$ Jean Jacques Noubiap, ${ }^{6}$ Joseph Kamgno ${ }^{1,7}$
}

To cite: Nansseu JR, Assah F, Petnga S-J, et al. Assessing the global risk of cardiovascular disease among a group of university students: populationbased cross-sectional study in Yaoundé, Cameroon. BMJ Open 2019;9:e030594. doi:10.1136/ bmjopen-2019-030594

- Prepublication history and additional material for this paper are available online. To view please visit the journal (http:// dx.doi.org/10.1136/bmjopen2019-030594).

Received 21 March 2019 Revised 23 July 2019 Accepted 23 August 2019
Check for updates

(C) Author(s) (or their employer(s)) 2019. Re-use permitted under CC BY-NC. No commercial re-use. See rights and permissions. Published by BMJ.

For numbered affiliations see end of article.

Correspondence to Dr Jobert Richie Nansseu; jobertrichie_nansseu@yahoo.fr

\section{ABSTRACT}

Objective To describe the global cardiovascular disease (CVD) risk distribution in a young adult-aged population living in Yaoundé, Cameroon and depict factors likely influencing this risk distribution.

Design A cross-sectional study between May and July 2017.

Setting The University of Yaoundé I, Cameroon.

Participants Any university student aged 18 years and above, with no known history of CVD, found at the campus during recruitment and who voluntarily agreed to be included in the study.

Primary and secondary outcome measures The global risk of CVD was measured with the non-laboratory-based INTERHEART Modifiable Risk Score.

Results A total of 949 participants (54\% males) were recruited; the median age was 23 (IQR 21-26) years. The CVD risk varied between 2 and 21, with a median of 9 (IQR 7-12); $51.2 \%$ of students had a low risk of CVD, $43.7 \%$ had a moderate risk and $5.1 \%$ presented a high risk of CVD. The number of years since first registration at the university $(\beta=0.08)$, history of sudden death among biological parents $(\beta=1.28)$, history of hypertension among brothers/sisters ( $\beta=1.33)$, history of HIV infection ( $\beta=4.34$ ), the Alcohol Use Disorder Identification Test-Consumption score $(\beta=0.13)$, regular exposure to firewood smoke $(\beta=1.29)$, eating foods/drinks with too much sugar $\geq 1$ time/day ( $\beta=0.96)$, eating foods/snacks with too much oil $\geq 3$ times/week $(\beta=1.20)$ and eating dairy products $\geq 1$ time/day $(\beta=0.61)$ were the independent factors likely influencing participants' global risk of CVD.

Conclusion Almost $50 \%$ of participants had moderate or high risk of CVD. Specific interventions targeting major CVD risk factors should be put in place among young adults to prevent or reduce this upcoming overburdened picture of CVD.

\section{INTRODUCTION}

Cardiovascular disease (CVD) is the leading cause of death globally and among the top killers in developing countries. In fact,
Strengths and limitations of this study

- This is the first study in Cameroon and Central Africa and one of the rare in sub-Saharan Africa which has evaluated the global risk of cardiovascular disease in a young adult-aged population.

- Singularly, we used a simple and cheaper tool, the non-laboratory-based INTERHEART Modifiable Risk Score which is adequate for resource-poor environments.

- There may have been some information bias, as a consequence of the fact that some parameters were self-reported.

- The method of sampling was not random; hence, the results may not be translatable to the entire population of young adult-aged Cameroonians.

the annual global mortality due to CVD is projected to increase from 17.5 million in 2012 to 22.2 million by 2030 , with about $80 \%$ occurring in developing countries. ${ }^{2}$ This high cardiovascular mortality in developing countries is fuelled by very low awareness, treatment and control rates of CVD risk factors such as hypertension, diabetes and dyslipidaemia added to the increase in life expectancy. ${ }^{3}$ Additionally, developing countries are undergoing rapid industrialisation and urbanisation. In fact, urbanisation, which is mediated by rapid economic development, may foster adverse effects relative to population health status. ${ }^{4}$ This negative influence directed particularly towards sedentary lifestyle may further magnify the risk of developing CVD.

There are sufficient data bolstering that CVD has a long life-course evolution with primordial risk factors starting as early as in childhood, adolescence or young 
adulthood..$^{5-9}$ Therefore, interventions put in place a long time before may prevent or delay CVD occurrence in adulthood. Moreover, the trend indicating CVD occurrence in late adulthood or old age is somewhat changing, as young populations are becoming more and more at risk of CVD than ever before. Recent preoccupying data indicate for instance an increasing incidence of stroke in younger age groups. ${ }^{10}{ }^{11}$ Additionally, there is convincing evidence showing a high prevalence of major CVD risk factors among younger populations. ${ }^{12-16}$ Consequently, there is urgent need for primary prevention among young populations before they reach adulthood. Accordingly, the CVD risk needs to be evaluated in these age groups as prescribes the Global Hearts Initiative, ${ }^{17}$ and appropriate measures taken to mitigate the current or future likelihood to develop CVD in order to avoid an overburdened picture of CVD in the next decades.

Some CVD risk assessment tools have been constructed to evaluate the global risk of developing a CVD event, one of which is the INTERHEART risk score. This tool was developed based on a multiethnic study sample from 52 countries of the world. ${ }^{18}$ This is considered to have an essential advantage over other models that were derived from American populations (the Framingham risk score) or primarily Caucasians (the Systematic Coronary Risk Evaluation score) and which had variable predictability in non-white populations. ${ }^{19}$ The generalisability of INTERHEART across diverse ethnic populations and geographic regions alongside the model comprehensiveness ${ }^{48}$ make INTERHEART more adequate and reliable for usage in a sub-Saharan African setting. Some previous studies have assessed the global risk of CVD among specific populations in Cameroon, ${ }^{20-23}$ but neither used the INTERHEART score nor were carried out in young people. Hence, in a context of complete absence of data, the present study intended to use the non-laboratory-based INTERHEART Modifiable Risk Score (IHMRS) to describe the global CVD risk distribution in a young adult-aged population living in Cameroon, a sub-Saharan African country. Additionally, it sought to investigate factors susceptible of influencing this risk distribution. The overarching goal of the present study was to identify and implement specific actions to mitigate the burden of CVD in the Cameroonian context and beyond. Actually, its results could be translatable to other sub-Saharan African or developing countries having similar patterns and/or challenges.

\section{METHODS}

\section{Study design, setting and participants}

This was a community-based cross-sectional study conducted from May to July 2017 at the University of Yaoundé I, Cameroon. Created in 1993, the University of Yaoundé $I$ is a public, scientific and cultural institution with legal personality and financial autonomy, placed under the supervision of the Cameroon Ministry of Higher Education. It comprises seven faculties and schools with students coming from all over the country.
Its headquarters are situated in Yaoundé, the capital city of Cameroon. The total number of students registered in this University was estimated at 73607 in $2017 .^{24}$

Participants were apparently healthy university students aged 18 years and above, regularly registered at the University of Yaoundé I during the 2016-2017 academic year, with no known history of CVD, found at the various campuses during recruitment and who voluntarily agreed to be included in the study. Pregnant women or those breast feeding were not considered in this study. Participants were consecutively recruited during the study period, using a non-probabilistic convenient sampling method. The minimal sample size was calculated based on the formula developed by Krejcie and Morgan: $S=Z^{2 *} N^{*} P *(1 P) /\left[d^{2 *}(N-1)+Z^{2} * P *(1 P)\right] .^{25}$ The confidence interval (CI) was fixed at $95 \%$; hence, $\mathrm{Z}^{2}=1.96$ and $\mathrm{d}=0.05$. The population proportion with global risk factors for CVD was assumed to be 0.5 since this would provide the maximum sample size. Considering a population size of 73607 students, the minimal sample size was calculated at 382 subjects.

\section{Data collection}

A standardised, anonymous, pretested and self-administered questionnaire served for data collection (online supplementary table 1). It comprised three sections: sociodemographic characteristics, medical history (family and personal medical history, lifestyle habits), and anthropometric and blood pressure (BP) measurements.

Students found wherever on the campuses, especially at various gathering places such as amphitheatres, laboratories, meeting rooms and restaurants were approached by the research team (composed of four medical doctors) on the different days of recruitment. Eligibility criteria were assessed by asking questions on existence of any CVD event in the past, age, registration to the study site and any current pregnancy or breastfeeding status (for female students). Then, the various aspects and procedures in relation with the study were presented to those who fulfilled these criteria. We recruited only those who volunteered to participate in the study; they signed a consent form in this regard. Afterwards, they filled the questionnaire and underwent a brief physical examination in the course of which weight, height, fat mass percentage, mid-upper arm, waist and hip circumferences and BP were measured. Each participant was subsequently briefed on healthy lifestyle habits, and those who were found with abnormal parameters were referred to the Medical and Social Welfare Centre of the University for further investigations and adequate care.

Specifically, alcohol consumption was assessed using the Alcohol Use Disorder Identification Test-Consumption (AUDIT-C) score; accordingly, hazardous alcohol drinking was considered on the basis of an AUDIT-G score $\geq 4$ for men, and $\geq 3$ for women. ${ }^{26}{ }^{27}$ Physical activity was evaluated with the Global Physical Activity Questionnaire, and classified into four groups. The first group was 'mainly sedentary': if the participant did not perform any physical 
activity, especially during leisure time. The second group, 'mild exercise', corresponded to easy walking for at least 10 min continuously several times in a week or moderate/ strenuous exercise but not responding to recommendations. The third group, 'moderate exercise', referred to any activity inducing a small increase in breathing or heart rate, performed during at least $30 \mathrm{~min}$ and at least 5 days per week. Lastly, the fourth group, 'strenuous exercise', was defined based on any activity causing a large increase in breathing or heart rate, performed during at least 25 min and at least 3 days per week. ${ }^{28} 29$

Height was measured to the nearest $0.5 \mathrm{~cm}$ using a standard rigid stadiometer, while weight (to the nearest $0.1 \mathrm{~kg}$ ) and fat mass percentage were measured with a body composition analyser (Tanita TBF-53 scales, Tanita UK, Yiewsley, Middlesex, UK). Body mass index (BMI) was derived as weight $(\mathrm{kg}) /$ height $^{2}\left(\mathrm{~m}^{2}\right)$ and subsequently grouped into four categories: underweight $(<18.5)$, normal (18.5-24.9), overweight (25.0-29.9) or obese $(\geq 30.0) .{ }^{30}$ Mid-upper arm, waist and hip circumferences were measured to the nearest $0.1 \mathrm{~cm}$ with a non-stretchable measuring tape. The mid-upper arm circumference was measured at the midpoint between the tip of the shoulder and the tip of the elbow. ${ }^{31}$ The waist circumference was measured at the midpoint between the top of the iliac crest and the lower margin of the last palpable rib in mid-axillary line while the hip circumference was measured at the largest circumference of the buttocks. ${ }^{32}$ Then, the waist-to-hip ratio was calculated as the waist circumference $(\mathrm{cm})$ divided by the hip circumference $(\mathrm{cm})$.

$\mathrm{BP}$ was measured using an electronic sphygmomanometer (Omron M5-1, Omron Healthcare, Kyoto, Japan), prior to which each participant had at least a 5 min rest at a seated position and the sphygmomanometer was calibrated. BP was measured thrice on the left arm at a $5 \mathrm{~min}$ interval, and the mean of these three measurements, given in $\mathrm{mm} \mathrm{Hg}$, was considered for further analyses. ${ }^{33}$

\section{Calculation of the non-laboratory-based IHMRS}

The global risk of CVD was determined using the non-laboratory-based IHMRS (online supplementary table 2). The score consists of 11 risk factors. ${ }^{19}$ Each positive risk factor was given the designated score. The total scores ranged from 0 to 48 , with the highest indicating greatest risk. The score was classified to low risk (score between 0 and 9), moderate risk (score between 10 and 15) and high risk (score between 16 and 48) based on previous studies. ${ }^{418} 19$

\section{Statistical procedures}

Data were coded, entered, cleaned and double checked using Microsoft Excel 2010. SPSS V.20.0 (SPSS IBM) and R V.3.3.1 (R Foundation for Statistical Computing, Vienna, Austria) served for data analysis. Results are mainly presented as median (IQR) for continuous variables (due to skewed distributions) and frequency (percentage) for categorical variables. Variable comparisons used the $\chi^{2}$ test or Fisher exact test, or the non-parametric tests (MannWhitney $\mathrm{U}$ test and Kruskal-Wallis $\mathrm{H}$ test), where applicable. Strength and direction of any relationship between quantitative variables were assessed using the Spearman correlation test and its rho $(\rho)$ coefficient. To assess the extent to which each of the various CVD risk factors may have influenced the global risk of CVD, univariable and multivariable linear regression analyses were used with their $\beta$ coefficient and $95 \%$ CIs. All factors used to derive the IHMRS were no more considered for these analyses. On the other hand, variables with a $p<0.25$ in univariable analyses were introduced in the multivariable model, in addition to components of BP (systolic and diastolic BP). Results were considered significant if $\mathrm{p}<0.05$.

\section{Patient and public involvement}

It was not appropriate or possible to involve patients or the public in this work.

\section{RESULTS}

Table 1 depicts the sociodemographic background of the study population. On the whole, 949 students were recruited, including $512(54.0 \%)$ men. The median age was 23 years (IQR 21-26). The most represented age group was 18-24 years $(65.4 \%)$. The two prevailing ethnic groups were Bantu (41.2\%) and Grassfield (40.5\%; table 1).

The global risk of CVD assessed using the IHMRS ranged from 2 to 21 points, with a median of 9 points (IQR $7-12)$. Four hundred and eighty-six students (51.2\%) had a low risk of CVD; 415 students (43.7\%) had a moderate risk, and 48 students $(5.1 \%)$ had a high risk of CVD in the next 10 years (figure 1 ). There was a positive and significant correlation between the IHMRS and the number of years since first registration at university $(\rho=0.082$; $\mathrm{p}=0.012)$, the AUDIT-C score $(\rho=0.088 ; \mathrm{p}=0.006)$, the BMI $(\rho=0.071 ; p=0.026)$ and the body fat mass percentage $(\rho=0.109 ; p=0.001)$, though these correlations were weak (table 2).

Table 3 presents the results of univariable and multivariable linear regression analyses to assess additional factors that may have independently influenced the risk of CVD among the study population. In the multivariable model, the Grassfield ethnic origin, the number of years since previous housing was left, the BMI, the mid-arm circumference and the body fat mass percentage were no more associated with the risk of CVD. The number of years since first registration at the University, history of sudden death among biological parents, history of hypertension among brothers/sisters, history of HIV infection, the AUDIT-C score, regular exposure to firewood smoke, eating foods/ drinks with too much sugar $\geq 1$ time/day, eating foods/ snacks with too much oil $\geq 3$ times/week and eating dairy products $\geq 1$ time/day were the independent factors likely influencing our participants' global risk of CVD occurrence (table 3 ). The adjusted coefficient of determination for this final model equalled $0.122(\mathrm{p}<2.2 \mathrm{e}-16)$. 
Table 1 General characteristics of the study population

\begin{tabular}{|ccc}
\hline Characteristic & $\begin{array}{l}\text { Number } \\
(\mathbf{n = 9 4 9 )}\end{array}$ & $\begin{array}{l}\text { Percentage } \\
(\%)\end{array}$ \\
\hline Age (years) & & \\
\hline $18-24$ & 621 & 65.4 \\
$25-34$ & 305 & 32.1 \\
\hline 35 & 23 & 2.4 \\
\hline Sex & & \\
$\quad$ Males & 512 & 54.0 \\
\hline Females & 437 & 46.0 \\
\hline
\end{tabular}

Level of study

$\begin{aligned} & \text { Undergraduate (in year three } \\ & \text { or less) }\end{aligned}$
$\begin{aligned} & \text { Graduate (in year four or } \\ & \text { above) }\end{aligned}$

$\begin{array}{lrr}\text { Religion } & & \\ \text { Christian } & 852 & 89.8 \\ \text { Muslim } & 73 & 7.7 \\ \text { Animist } & 8 & 0.8 \\ \text { Other } & 16 & 1.7\end{array}$

Ethnic origin

\begin{tabular}{lrr}
\hline Sudano-Sahelian & 76 & 8.0 \\
\hline Sawa & 98 & 10.3 \\
\hline Grassfield & 384 & 40.5 \\
\hline Bantu & 391 & 41.2 \\
\hline Marital status & & \\
\hline Single & 875 & 92.2 \\
\hline Divorced & 0 & 0.0 \\
\hline Widow(er) & 2 & 0.2 \\
\hline Married & 44 & 4.6 \\
\hline Concubinage & 28 & 3.0 \\
\hline Housing & & \\
\hline Lives alone & 289 & 30.4 \\
\hline Lives in family & 575 & 60.6 \\
\hline Lives in colocation & 85 & 9.0 \\
\hline Environment before university & & \\
\hline Urban & 694 & 73.1 \\
\hline Semiurban & 165 & 17.4 \\
\hline Rural & 90 & 9.5 \\
\hline
\end{tabular}

\section{DISCUSSION}

This study enrolled 949 young adults living in Yaoundé, Cameroon and revealed that $43.7 \%$ and $5.1 \%$ of participants, respectively, had a moderate and high risk of developing a CVD event in the near future if nothing is done. Moreover, it was found that the number of years since first registration at the university, history of sudden death among biological parents, history of hypertension among brothers/sisters, history of HIV infection, the AUDIT-C score, regular exposure to firewood smoke, eating foods/

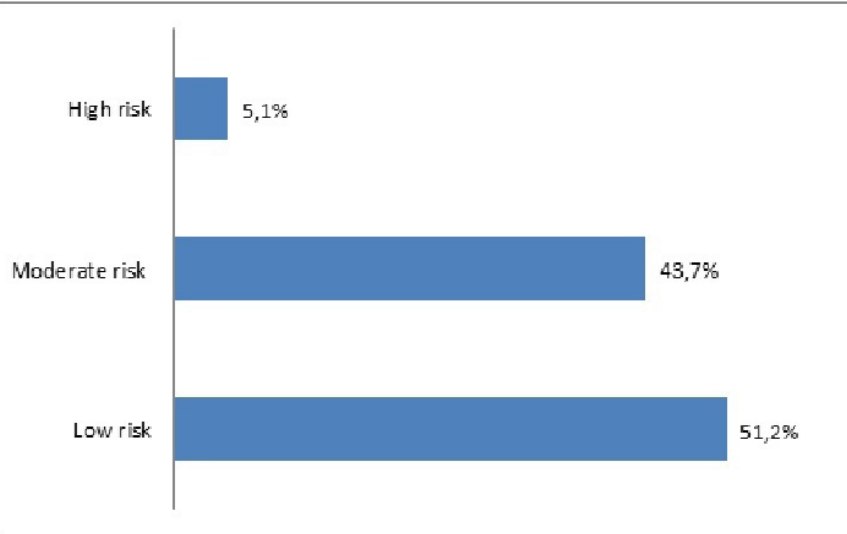

Figure 1 Distribution of the cardiovascular risk among the study population.

drinks with too much sugar $\geq 1$ time/day, eating foods/ snacks with too much oil $\geq 3$ times/week and eating dairy products $\geq 1$ time/day were the factors likely influencing the global risk of CVD.

This high number of young adults identified with a moderate risk of CVD is preoccupying, as they may shift into the high risk stratum in the near future if nothing is done. Feigin et al showed that the largest contributors to the stroke burden are behavioural factors (smoking, poor diet and low physical activity), followed by metabolic factors (high systolic BP, high BMI, high fasting plasma glucose, high total cholesterol and low glomerular filtration rate) and environmental factors (air pollution and lead pollution). ${ }^{34}$ The present study clearly identified some of these factors, perhaps inferring that if specific interventions targeting each of these factors are implemented, the projected overburdened picture of CVD would be efficaciously mitigated in the Cameroonian context and beyond. Moreover, the debate of initiating

Table 2 Correlation between the cardiovascular risk score and other continuous parameters

\begin{tabular}{lcl}
\hline Variable & $\begin{array}{l}\text { Coefficient of } \\
\text { correlation }(\boldsymbol{\rho})\end{array}$ & P value \\
\hline $\begin{array}{l}\text { Years since previous housing } \\
\text { was left }\end{array}$ & 0.044 & 0.176 \\
\hline $\begin{array}{l}\text { Years since first registration } \\
\text { AUDIT-C score }\end{array}$ & 0.082 & $0.012^{*}$ \\
\hline $\begin{array}{l}\text { Exposure to firewood smoke } \\
\text { (hours/week) } \mathrm{n}=131\end{array}$ & 0.088 & $0.006^{*}$ \\
\hline $\begin{array}{l}\text { Systolic blood pressure } \\
\text { Diastolic blood pressure }\end{array}$ & 0.015 & 0.456 \\
\hline Mid-arm circumference & 0.032 & 0.654 \\
\hline Body fat mass percentage & 0.109 & 0.331 \\
\hline Body mass index & 0.071 & 0.167 \\
\hline
\end{tabular}

${ }^{*} \mathrm{p}<0.05$.

AUDIT-C, Alcohol Use Disorder Identification Test-Consumption Questionnaire. 
Table 3 Univariable and multivariable linear regression analyses to seek factors that may have influenced the global risk of cardiovascular disease among the study population

\begin{tabular}{|c|c|c|c|c|c|}
\hline \multicolumn{2}{|l|}{ Parameter } & $\beta$ coefficient $(95 \% \mathrm{Cl})$ & $P$ value & $\begin{array}{l}\text { Adjusted } \beta \dagger \\
\text { coefficient } \\
(95 \% \mathrm{Cl})\end{array}$ & $P$ value \\
\hline \multicolumn{2}{|c|}{ Level of study: graduate } & $\begin{array}{l}0.075 \\
(-0.359 \text { to } 0.509)\end{array}$ & 0.735 & / & \\
\hline \multicolumn{2}{|c|}{ Marital status: in couple } & $\begin{array}{l}0.160 \\
(-0.242 \text { to } 0.563)\end{array}$ & 0.434 & / & \\
\hline \multirow[t]{4}{*}{ Religion } & Animist & Ref & & l & \\
\hline & Christian & $\begin{array}{l}-0.278 \\
(-2.665 \text { to } 2.110)\end{array}$ & 0.820 & / & \\
\hline & Muslim & $\begin{array}{l}-0.355 \\
(-2.858 \text { to } 2.149)\end{array}$ & 0.781 & / & \\
\hline & Other & $\begin{array}{l}0.250 \\
\text { (3.161 to } 2.661)\end{array}$ & 0.866 & / & \\
\hline \multirow[t]{4}{*}{ Ethnicity } & Bantu & Ref & & & \\
\hline & Sudano-Sahelian & $\begin{array}{l}-0.534 \\
(-0.903 \text { to } 0.778)\end{array}$ & 0.8846 & $\begin{array}{l}0.188 \\
(-0.620 \text { to } 0.997)\end{array}$ & 0.647405 \\
\hline & Sawa & $\begin{array}{l}-0.352 \\
(-1.109 \text { to } 0.406)\end{array}$ & 0.3624 & $\begin{array}{l}0.017 \\
(-0.710 \text { to } 0.745)\end{array}$ & 0.963125 \\
\hline & Grassfield & $\begin{array}{l}-0.534 \\
(-1.016 \text { to } 0.052)\end{array}$ & $0.0298^{\star \star}$ & $\begin{array}{l}-0.268 \\
(-0.742 \text { to } 0.205)\end{array}$ & 0.266381 \\
\hline \multirow[t]{3}{*}{ Housing } & Lives in colocation & Ref & & / & \\
\hline & Lives alone & $\begin{array}{l}-0.454 \\
(-1.282 \text { to } 0.374)\end{array}$ & 0.282 & / & \\
\hline & Lives in family & $\begin{array}{l}-0.111 \\
(-0.891 \text { to } 0.669)\end{array}$ & 0.779 & / & \\
\hline \multirow{3}{*}{$\begin{array}{l}\text { Environment before } \\
\text { university }\end{array}$} & Rural & Ref & & & \\
\hline & Urban & $\begin{array}{l}0.514 \\
(-0.238 \text { to } 1.265)\end{array}$ & $0.180^{\star}$ & $\begin{array}{l}0.481 \\
(-0.253 \text { to } 1.215)\end{array}$ & 0.199001 \\
\hline & Semiurban & $\begin{array}{l}0.043 \\
(-0.835 \text { to } 0.922)\end{array}$ & 0.923 & $\begin{array}{l}0.070 \\
(-0.766 \text { to } 0.907)\end{array}$ & 0.868799 \\
\hline \multicolumn{2}{|c|}{$\begin{array}{l}\text { Years since previous housing was left } \\
\text { (years) }\end{array}$} & $\begin{array}{l}0.066 \\
(0.011 \text { to } 0.121)\end{array}$ & $0.019^{* *}$ & $\begin{array}{l}0.051 \\
(-0.007 \text { to } 0.109)\end{array}$ & 0.083301 \\
\hline \multicolumn{2}{|c|}{ Years since first registration (years) } & $\begin{array}{l}0.104 \\
(0.022 \text { to } 0.185)\end{array}$ & $0.0128^{\star \star}$ & $\begin{array}{l}0.084 \\
(0.0002 \text { to } 0.167)\end{array}$ & $0.049380^{\star \star}$ \\
\hline \multicolumn{2}{|c|}{$\begin{array}{l}\text { No history of stroke among biological } \\
\text { parents }\end{array}$} & $\begin{array}{l}-0.825 \\
(-1.719 \text { to } 0.070)\end{array}$ & $0.0707^{\star}$ & $\begin{array}{l}-0.452 \\
(-1.323 \text { to } 0.420)\end{array}$ & 0.309424 \\
\hline \multicolumn{2}{|c|}{$\begin{array}{l}\text { No history of sudden death among } \\
\text { biological parents }\end{array}$} & $\begin{array}{l}-1.608 \\
(-2.535 \text { to } 0.681)\end{array}$ & $0.000694^{\star *}$ & $\begin{array}{l}-1.283 \\
(-2.178 \text { to } 0.389)\end{array}$ & $0.004963^{\star *}$ \\
\hline \multicolumn{2}{|c|}{$\begin{array}{l}\text { No history of hypertension among } \\
\text { biological parents }\end{array}$} & $\begin{array}{l}-0.347 \\
(-0.815 \text { to } 0.120)\end{array}$ & $0.145^{\star}$ & $\begin{array}{l}-0.163 \\
(-0.632 \text { to } 0.306)\end{array}$ & 0.496250 \\
\hline \multicolumn{2}{|c|}{$\begin{array}{l}\text { No history of diabetes among biological } \\
\text { parents }\end{array}$} & $\begin{array}{l}-0.522 \\
(-1.117 \text { to } 0.073)\end{array}$ & $0.0856^{*}$ & $\begin{array}{l}-0.135 \\
(-0.728 \text { to } 0.458)\end{array}$ & 0.655998 \\
\hline \multicolumn{2}{|c|}{$\begin{array}{l}\text { No history of hypertension among } \\
\text { brothers/sisters }\end{array}$} & $\begin{array}{l}-1.7601 \\
(-2.852 \text { to } 0.668)\end{array}$ & $0.00162^{\star *}$ & $\begin{array}{l}-1.325 \\
(-2.397 \text { to } 0.254)\end{array}$ & $0.015401^{* *}$ \\
\hline \multicolumn{2}{|c|}{$\begin{array}{l}\text { No history of diabetes among brothers/ } \\
\text { sisters }\end{array}$} & $\begin{array}{l}-1.273 \\
(-2.827 \text { to } 0.281)\end{array}$ & $0.108^{\star}$ & $\begin{array}{l}-0.179 \\
(-1.703 \text { to } 1.345)\end{array}$ & 0.817625 \\
\hline \multicolumn{2}{|c|}{ No existence of another chronic NCD } & $\begin{array}{l}-0.540 \\
(-2.233 \text { to } 1.153)\end{array}$ & 0.532 & / & \\
\hline \multicolumn{2}{|c|}{ No known HIV infection } & $\begin{array}{l}-4.085 \\
(-7.960 \text { to } 0.211)\end{array}$ & $0.0388^{\star \star}$ & $\begin{array}{l}-4.341 \\
(-8.074 \text { to } 0.608)\end{array}$ & $0.022718^{\star \star}$ \\
\hline
\end{tabular}


Table 3 Continued

\begin{tabular}{|c|c|c|c|c|}
\hline Parameter & $\beta$ coefficient $(95 \% \mathrm{Cl})$ & $P$ value & $\begin{array}{l}\text { Adjusted } \beta \dagger \\
\text { coefficient } \\
\text { (95\% Cl) }\end{array}$ & $P$ value \\
\hline AUDIT-C score & $\begin{array}{l}0.18024 \\
(0.087 \text { to } 0.274)\end{array}$ & $0.00016^{\star *}$ & $\begin{array}{l}0.130 \\
(0.037 \text { to } 0.224)\end{array}$ & $0.006290^{\star *}$ \\
\hline No regular exposure to firewood smoke & $\begin{array}{l}-1.585 \\
(-2.178 \text { to } 0.993)\end{array}$ & $1.85 \mathrm{e}-07^{\star \star}$ & $\begin{array}{l}-1.289 \\
(-1.863 \text { to } 0.715)\end{array}$ & $1.18 \mathrm{e}-05^{\star \star}$ \\
\hline $\begin{array}{l}\text { Exposure to firewood smoke (hours/ } \\
\text { week) } n=131\end{array}$ & $\begin{array}{l}-0.030 \\
(-0.081 \text { to } 0.021)\end{array}$ & 0.25 & / & \\
\hline $\begin{array}{l}\text { Not eating foods/drinks containing too } \\
\text { much sugar one or more times a day }\end{array}$ & $\begin{array}{l}-1.138 \\
(-1.719 \text { to } 0.558)\end{array}$ & $0.000128^{\star \star}$ & $\begin{array}{l}-0.960 \\
(-1.526 \text { to } 0.393)\end{array}$ & $0.000922^{\star \star}$ \\
\hline $\begin{array}{l}\text { Not eating oily foods/snacks one or more } \\
\text { times a day }\end{array}$ & $\begin{array}{l}-1.361 \ddagger \\
(-1.790 \text { to } 0.932)\end{array}$ & $7.3 e-10^{\star \star}$ & / & \\
\hline $\begin{array}{l}\text { Not eating oily foods/snacks three or } \\
\text { more times a week }\end{array}$ & $\begin{array}{l}-1.388 \ddagger \\
(-1.816 \text { to } 0.961)\end{array}$ & $2.82 \mathrm{e}-10^{\star *}$ & $\begin{array}{l}-1.198 \\
(-1.617 \text { to } 0.779)\end{array}$ & $2.70 \mathrm{e}-08^{\star \star}$ \\
\hline $\begin{array}{l}\text { Not eating dairy products one or more } \\
\text { times a day }\end{array}$ & $\begin{array}{l}-0.7973 \ddagger \\
(-1.239 \text { to } 0.356\end{array}$ & $0.000414^{\star *}$ & $\begin{array}{l}-0.609 \\
(-1.051 \text { to } 0.167)\end{array}$ & $0.006966^{\star \star}$ \\
\hline $\begin{array}{l}\text { Not eating dairy products three or more } \\
\text { times a week }\end{array}$ & $\begin{array}{l}-0.5040 \ddagger \\
(-0.946 \text { to } 0.062)\end{array}$ & $0.0254^{\star \star}$ & / & \\
\hline Body mass index $\left(\mathrm{kg} / \mathrm{m}^{2}\right)$ & $\begin{array}{l}0.098 \\
(0.036 \text { to } 0.160)\end{array}$ & $0.00186^{\star \star}$ & $\begin{array}{l}0.041 \\
(-0.071 \text { to } 0.152)\end{array}$ & 0.477888 \\
\hline Mid-arm circumference (cm) & $\begin{array}{l}0.0792 \\
(0.006 \text { to } 0.152)\end{array}$ & $0.0342^{\star *}$ & $\begin{array}{l}-0.006752 \\
(-0.116 \text { to } 0.103)\end{array}$ & 0.903642 \\
\hline Systolic blood pressure $(\mathrm{mm} \mathrm{Hg})$ & $0.007(-0.012$ to 0.026$)$ & 0.494 & $\begin{array}{l}-0.001 \\
(-0.031 \text { to } 0.028)\end{array}$ & 0.935044 \\
\hline Diastolic blood pressure $(\mathrm{mm} \mathrm{Hg})$ & $\begin{array}{l}0.01576 \\
(-0.011 \text { to } 0.042)\end{array}$ & $0.246^{*}$ & $\begin{array}{l}-0.006 \\
(-0.032 \text { to } 0.021)\end{array}$ & 0.680012 \\
\hline Body fat mass percentage (\%) & $\begin{array}{l}0.038 \\
(0.014 \text { to } 0.062)\end{array}$ & $0.00179^{\star *}$ & $\begin{array}{l}0.021 \\
(-0.011 \text { to } 0.052)\end{array}$ & 0.202238 \\
\hline
\end{tabular}

${ }^{*} \mathrm{p}<0.25 ;{ }^{* *} \mathrm{p}<0.05$.

†All variables with a $p<0.25$ in univariable analysis were introduced in the multivariable model.

$\ddagger$ Parameters for which the $\mathrm{R}^{2}$ was higher in univariable analysis were introduced in the multivariable model.

AUDIT-C, Alcohol Use Disorder Identification Test-Consumption Questionnaire; NCD, non-communicable disease.

a pharmacological treatment for the prevention of CVD among high-risk populations is still ongoing; a polypill made of an antihypertensive drug, a statin and inconstantly a low-dose anticoagulant is suggested to be initiated in high-risk primary prevention of CVD, but the evidence supporting this recommendation is very weak. ${ }^{35-37}$

Univariable and multivariable linear regression analyses were undertaken to depict factors susceptible of influencing the risk of CVD. In univariable analyses, level of study, marital status, religion, housing, environment before university, history of stroke/hypertension/ diabetes among biological parents, history of diabetes among brothers/sisters, existence of another chronic non-communicable disease, systolic BP and diastolic BP were not associated with the IHMRS (all $p$ values $>0.05$ ). Specifically and intriguingly, systolic BP and diastolic BP did not have any influence on the participants' risk of CVD, after both univariable and multivariable linear regression analysis. This is in contrast with findings from Ama Moor et al. according to which diastolic BP was independently influencing their respondents' risk of CVD, systolic BP being included in the Framingham Risk Score. ${ }^{21}$ The present results may be explained by the fact that the very large majority of respondents had normal BP levels (only 3.1\% with BP levels $\geq 140 / 90 \mathrm{~mm}$ $\mathrm{Hg}$ ). Nonetheless, further studies are required to better elucidate this issue.

Furthermore, the multivariable analysis identified other factors likely impacting the future risk of CVD among the study's respondents. For instance, there is currently no doubt that HIV infection is a big driver of CVD. Gutierrez et al. showed indeed that HIV infection was an independent risk factor for death, any coronary heart disease, any stroke, ischaemic stroke and intracranial haemorrhage. ${ }^{38}$ The pathophysiology behind the increased risk of CVD among people with HIV infection is multifactorial, mainly supported by two metabolic disorders including dyslipidaemia and insulin resistance, very well known as CVD risk factors. Both conditions result from the probable complex interaction between the host's advancing age, 
the virus, the inflammatory process and the continuous highly active antiretroviral therapy. ${ }^{39} 40$ It was therefore not surprising that HIV-positive students had higher risk scores than their counterparts (median score 14 vs $9 ; p=0.030$ ); additionally, results of multivariable analysis figured out that HIV-infected students were likely to have a 4.34-point higher score than HIV-negative students. These results indicate perhaps that the HIV-positive status must be taken into consideration when developing local tools for CVD risk assessment.

It was also found that each 1-point increment in the AUDIT-C score could potentially lead to a 0.13-point increase in the IHMRS, confirming hazardous alcohol consumption as a risk factor for CVD, ${ }^{3}{ }^{41} 42$ which shall thereby be considered when assessing this risk. Likewise, it was observed that people who were regularly exposed to firewood smoke were likely to have a 1.29-point higher risk of CVD than their counterparts who were not regularly exposed. This finding is in line with the current evidence pointing air pollution as a risk factor for CVD. ${ }^{34}$

Each additional year since first registration at the university was likely accompanied by a 0.1 -point increase in the risk of CVD, explained perhaps by the increasing level of stress as the level of studies increases. Besides, students with a history of sudden death among either or both of biological parents, a history of hypertension among brothers/sisters, those consuming foods/drinks containing too much sugar one or more times a day, oily foods/snacks $\geq 3$ times/week, and those eating dairy products $\geq 1$ time/day were likely to have a 1.28-point, 1.33-point, 0.96-point, 1.2-point and a 0.69-point higher risk of CVD than their counterparts, respectively. Therefore, further studies are warranted, which will permit to identify further potential factors susceptible of impacting the risk of CVD. These factors would be included in a model and tested to determine an accurate risk estimator adapted for the sub-Saharan African context.

Nevertheless, the present results should be interpreted in the context of some limitations. First, its cross-sectional design precludes from concluding that the factors that have been identified are real predictors/drivers of future CVD occurrence among young adults in the local context. Second, the study included only educated participants enrolled from only one academic institution and on a consecutive rather than a random basis, which may have induced some selection biases, thus impeding the translatability of results to the entire young adult-aged population living in Cameroon. However, the University of Yaoundé I receives students coming from all over the country; hence, it may reflect all the diversity of the Cameroonian young adult-aged population. Additionally, the research team made no distinction/restriction when approaching potential participants to invite them, which may have attenuated the impact of selection biases. Third, there may be some information biases, due to the fact that it could not be objectively possible to confirm each of the participants' responses to questions; as a consequence, some parameters may have been underestimated (such as the HIV status, smoking and secondhand smoking habits) or overestimated (for example, physical activity and fruits / vegetables consumption). Nevertheless, participants were sensitised to provide the most objective and trustworthy answers when filling the questionnaire. Fourth, the questionnaire that was used had not yet been pilot tested in Cameroon, which needs to be amended in future similar studies. Fifth, in the absence of locally developed tools to assess the global risk of CVD in the general population, the IHMRS which has not yet been validated locally, was used. ${ }^{18}{ }^{19}$ Moreover and like other scores, the IHMRS was mainly used among older populations. Therefore, its applicability among younger aged groups could be questionable, even though to the very best of our knowledge the IHMRS, which derives from the Framingham Risk Score, was not misadvised for people aged below 40-50 years. In this regard, specific CVD risk estimators need to be developed for younger populations. The IHMRS identifies mainly the future risk of developing a myocardial infarction rather than stroke; it may thereby be less accurate for African populations who may present more cases of stroke rather than myocardial infarction. ${ }^{14143}$ Accordingly, there is crucial need for prospective cohort studies which will enable to accurately describe the patterns of CVD in African settings and develop local tools for CVD risk assessment and subsequent prevention.

Notwithstanding and to the best of our knowledge, no previous study had yet assessed the global risk of CVD among young adults living in Cameroon and even in Central Africa. The non-laboratory-based IHMRS was used, which does not include laboratory measurements of lipid levels. It offers the advantage of being simple and very cheap; hence, it is of significant interest for economically deprived areas with lack of equipped laboratories. ${ }^{435}$ There is sufficient evidence highlighting the comparability of this tool to laboratory-based CVD risk estimators in predicting future occurrence of CVD. ${ }^{19}{ }^{44-46}$ Furthermore, strong and rigorous statistical procedures were applied to adequately address the research questions. The sample size was high, more than twice the required minimal sample size. Participants were recruited in the community, which has the advantage of reflecting the true picture of the disease burden. Considering that this study is the first in the country to use the IHMRS, the present findings provide further impetus to healthcare providers to start using this CVD risk estimator for routine cardiovascular events prediction.

\section{CONCLUSION}

This study carried out among students of the University of Yaoundé I, Cameroon showed that almost $50 \%$ of participants presented a moderate to high risk of CVD in the near future. Some factors were identified to likely influence the risk of CVD, among which alcohol consumption, HIV infection, exposure to firewood smoke and consumption of too much sugar, oil and dairy products. Consequently, the burden of CVD will increase in the 
country if nothing is done. Strong and effective interventions targeting these specific CVD risk factors should be put in place among young adults, in order to prevent or reduce this upcoming overburdened picture of CVD.

\section{Author affiliations}

${ }^{1}$ Department of Public Health, Faculty of Medicine and Biomedical Sciences of the University of Yaoundé I, Yaoundé, Cameroon

${ }^{2}$ Department for the Control of Disease, Epidemics and Pandemics, Ministry of Public Health, Yaoundé, Cameroon

${ }^{3}$ Kousseri Regional Hospital, Far-North Regional Delegation, Ministry of Public Health, Kousseri, Cameroon

${ }^{4}$ HIV Care Unit, Ngaoundéré Regional Hospital and Regional Technical Group for the Fight Against HIV/AIDS, Adamawa Regional Delegation, Ministry of Public Health, Ngaoundere, Cameroon

${ }^{5}$ Faculty of Medicine and Biomedical Sciences, University of Yaoundé I, Yaoundé, Cameroon

${ }^{6}$ Department of Medicine, University of Cape Town and Groote Schuur Hospital, Cape Town, South Africa

${ }^{7}$ Centre for Research on Filariasis and other Tropical Diseases, Yaoundé, Cameroon

Acknowledgements The authors are grateful to the Rectorate of the University of Yaoundé I who authorised this study, and to all those who volunteered to take part in it. Additionally, they thank Shalom Ndoula Tchokfe, Emmanuel Armand Kouotou, Pierre Alain Ndzengue Ngono, Dahlia Noelle Ndanga Tounouga, Jean Jacques Baye Yomkil and Suzel Valère Tagatsi Tala for their help in conceiving the study, collecting the data and/or reviewing the manuscript.

Contributors JRN, FA, JJN and JK conceived and designed the study. SJP, JRN, BSK, HDFT, FTN and DLAW collected the data. JRN, BSK and JJN analysed and interpreted the data. JRN wrote the first draft of the manuscript. FA, JK, SJP, BSK, JJN, HDFT, FTN and DLAW reviewed and revised the manuscript. All authors approved the final version of the manuscript. JRN is the guarantor for this study.

Funding The authors have not declared a specific grant for this research from any funding agency in the public, commercial or not-for-profit sectors.

Competing interests None declared.

Patient consent for publication Not required.

Ethics approval Before initiation of this study, an ethical clearance was granted by the Cameroon Bioethics Initiative Ethics Review and Consultancy Committee (reference CBI/404/ERCC/CAMBIN). Additionally, an administrative authorisation was issued by the Rectorate of the University of Yaoundé I, Cameroon. A protocol was written before starting the study, which procedures complied with the current revision of the Helsinki Declaration.All study aspects and procedures were fully presented and explained to each potential participant using an information notice. In the end, those who were included were exclusively volunteering participants. They signed a consent form, accordingly. Their identity was kept anonymous, and respective information gathered, kept confidential

Provenance and peer review Not commissioned; externally peer reviewed.

Data availability statement Data are available upon reasonable request.

Open access This is an open access article distributed in accordance with the Creative Commons Attribution Non Commercial (CC BY-NC 4.0) license, which permits others to distribute, remix, adapt, build upon this work non-commercially, and license their derivative works on different terms, provided the original work is properly cited, appropriate credit is given, any changes made indicated, and the use is non-commercial. See: http://creativecommons.org/licenses/by-nc/4.0/.

\section{REFERENCES}

1. Vos T, Allen C, Arora M, et al. Global, regional, and national incidence, prevalence, and years lived with disability for 310 diseases and injuries, 1990-2015: a systematic analysis for the global burden of disease study 2015. The Lancet 2016;388:1545-602.

2. World Health Organization. WHO | The Atlas of Heart Disease and Stroke [Internet]. WHO, 2017. Available: http://www.who.int/ cardiovascular_diseases/resources/atlas/en/ [Accessed 20 Aug 2017].

3. Forouzanfar MH, Afshin A, Alexander LT, et al. Global, regional, and national comparative risk assessment of 79 behavioural, environmental and occupational, and metabolic risks or clusters of risks, 1990-2015: a systematic analysis for the global burden of disease study 2015. The Lancet 2016;388:1659-724.

4. Hassim N I, Norazman MR, Diana M, et al. Cardiovascular risk assessment between urban and rural population in Malaysia. Med $\mathrm{J}$ Malaysia 2016;71:331-7.

5. Chu C, Dai Y, Mu J, et al. Associations of risk factors in childhood with arterial stiffness 26 years later: the Hanzhong adolescent hypertension cohort. J Hypertens 2017;35(Suppl 1):S10-15.

6. Laitinen TT, Pahkala K, Venn A, et al. Childhood lifestyle and clinical determinants of adult ideal cardiovascular health: the cardiovascular risk in young Finns study, the childhood determinants of adult health study, the Princeton follow-up study. Int J Cardiol 2013;169:126-32.

7. Shah RV, Murthy VL, Colangelo LA, et al. Association of fitness in young adulthood with survival and cardiovascular risk: the coronary artery risk development in young adults (cardia) study. JAMA Intern Med 2016;176:87-95.

8. Yano Y, Reis JP, Tedla YG, et al. Racial differences in associations of blood pressure components in young adulthood with incident cardiovascular disease by middle age: coronary artery risk development in young adults (cardia) study. JAMA Cardiol 2017;2:381-9.

9. Noubiap JJ, Essouma M, Bigna JJ, et al. Prevalence of elevated blood pressure in children and adolescents in Africa: a systematic review and meta-analysis. The Lancet Public Health 2017;2:e375-86.

10. Kissela BM, Khoury JC, Alwell K, et al. Age at stroke: temporal trends in stroke incidence in a large, biracial population. Neurology 2012;79:1781-7.

11. Smajlović D. Strokes in young adults: epidemiology and prevention. Vasc Health Risk Manag 2015;11:157-64.

12. Ali M, Yusuf HI, Stahmer J, et al. Cardiovascular risk factors and physical activity among university students in Somaliland. $J$ Community Health 2015;40:326-30.

13. Mandengue SH, Bita Fouda AA, Epacka Ewane M, et al. Epidemiologiy of obesity among university students in Douala, Cameroon. Med Sante Trop 2015;25:386-91.

14. Mbatchou Ngahane BH, Luma H, Mapoure YN, et al. Correlates of cigarette smoking among university students in Cameroon. int $j$ tuberc lung dis 2013;17:270-4.

15. Nyombi KV, Kizito S, Mukunya D, et al. High prevalence of hypertension and cardiovascular disease risk factors among medical students at Makerere University College of health sciences, Kampala, Uganda. BMC Res Notes 2016;9:110.

16. Tadesse $T$, Alemu $H$. Hypertension and associated factors among university students in Gondar, Ethiopia: a cross-sectional study. BMC Public Health 2014;14:937.

17. WHO. WHO | New initiative launched to tackle cardiovascular disease, the world's number one killer [Internet], 2019. Available: http://www.who.int/cardiovascular_diseases/global-hearts/Global_ hearts_initiative/en/ [Accessed 26 Jun 2019].

18. Yusuf $S$, Hawken S, Ônpuu S, et al. Effect of potentially modifiable risk factors associated with myocardial infarction in 52 countries (the INTERHEART study): case-control study. The Lancet 2004;364:937-52.

19. McGorrian C, Yusuf S, Islam S, et al. Estimating modifiable coronary heart disease risk in multiple regions of the world: the INTERHEART modifiable risk score. Eur Heart J 2011;32:581-9.

20. Ama Moor VJ, Nansseu JRN, Azingni DBT, et al. Assessment of the 10-year risk of cardiovascular disease among a group of patients on maintenance hemodialysis: a cross-sectional study from Cameroon. JRSM Cardiovasc Dis 2017;004017705273.

21. Ama Moor VJ, Nansseu JRN, Nouaga MED, et al. Assessment of the 10-year risk of cardiovascular events among a group of sub-Saharan African post-menopausal women. Cardiol J 2016;23:123-31.

22. Nansseu JRN, Moor VJA, Nouaga MED, et al. Atherogenic index of plasma and risk of cardiovascular disease among Cameroonian postmenopausal women. Lipids Health Dis 2016;15:49.

23. Noumegni SR, Ama VJM, Assah FK, et al. Assessment of the agreement between the Framingham and dad risk equations for estimating cardiovascular risk in adult Africans living with HIV infection: a cross-sectional study. Trop Dis Travel Med Vaccines $2017 ; 3$.

24. The Unversity of Yaoundé I. The University of Yaoundé I - About Us [Internet], 2016. Available: http://www.webuy1.uninet.cm/uy1/index. php?option=com_content\&view=article\&id=21\&ltemid=112\&lang=en [Accessed 20 Aug 2017].

25. Krejcie RV, Morgan DW. Determining sample size for research activities. Educ Psychol Meas 1970;30:607-10.

26. Bush K, Kivlahan DR, McDonell MB, et al. The audit alcohol consumption questions (AUDIT-C): an effective brief screening test for problem drinking. ambulatory care quality improvement project 
(ACQUIP). alcohol use disorders identification test. Arch Intern Med 1998;158:1789-95.

27. Bradley KA, Bush KR, Epler AJ, et al. Two brief alcohol-screening tests from the alcohol use disorders identification test (audit): validation in a female Veterans Affairs patient population. Arch Intern Med 2003;163:821-9.

28. American Heart Association. American Heart Association Recommendations for Physical Activity in Adults [Internet], 2015. Available: http://www.heart.org/HEARTORG/HealthyLiving/ PhysicalActivity/FitnessBasics/American-Heart-AssociationRecommendations-for-Physical-Activity-in-Adults_UCM_307976_ Article.jsp\#.WZkhMennqM8 [Accessed 20 Aug 2017].

29. World Health Organization. Global Physical Activity Questionnaire - World Health Organization [Internet]. Available: www.who.int/chp/ steps/GPAQ_EN.pdf?ua=1 [Accessed 14 Feb 2017].

30. World Health Organization. Obesity: preventing and managing the global epidemic. Report of a who consultation Report No.: World Health Organ Tech Rep Ser. 2000;894:i - xii. Geneva, Switzerland: World Health Organization, 2000: 1-253.

31. Yallamraju SR, Mehrotra R, Sinha A, et al. Use of mid upper arm circumference for evaluation of nutritional status of OSMF patients. $J$ Int Soc Prev Community Dent 2014;4(Suppl 2):S122-5.

32. World Health Organization. Waist circumference and waist-hip ratio: report of a who expert consultation, Geneva, 8-11 December 2008. Geneva, Switzerland: World Health Organization, 2011.

33. Chobanian AV, Bakris GL, Black HR, et al. The seventh report of the joint National Committee on prevention, detection, evaluation, and treatment of high blood pressure: the JNC 7 report. JAMA 2003;289:2560-72.

34. Feigin VL, Roth GA, Naghavi M, et al. Global burden of stroke and risk factors in 188 countries, during 1990-2013: a systematic analysis for the global burden of disease study 2013. Lancet Neurol 2016;15:913-24.

35. Nansseu JRN, Noubiap JJN. Aspirin for primary prevention of cardiovascular disease. Thromb J 2015;13:38.

36. Noubiap JJN, Nansseu JR. Are the current recommendations for the use of aspirin in primary prevention of cardiovascular disease applicable in low-income countries? Vasc Health Risk Manag 2015;11:503-6.
37. Nansseu JRN, Tankeu AT, Kamtchum-Tatuene J, et al. A fixeddose combination therapy to reduce the growing burden of cardiovascular disease in low- and middle-income countries: feasibility and challenges. J Clin Hypertens Greenwich Conn. In Press;2017.

38. Gutierrez J, Albuquerque ALA, Falzon L. Hiv infection as vascular risk: a systematic review of the literature and meta-analysis. PLoS One 2017;12:e0176686.

39. Kiage JN, Heimburger DC, Nyirenda CK, et al. Cardiometabolic risk factors among HIV patients on antiretroviral therapy. Lipids Health Dis 2013;12:50.

40. Noumegni SR, Bigna JJ, Ama Moor epse Nkegoum VJ, et al. Relationship between estimated cardiovascular disease risk and insulin resistance in a black African population living with HIV: a cross-sectional study from Cameroon. BMJ Open 2017;7:e016835.

41. Keates AK, Mocumbi AO, Ntsekhe M, et al. Cardiovascular disease in Africa: epidemiological profile and challenges. Nat Rev Cardiol 2017;14:273-93.

42. World Health Organization. WHO Media Centre | Cardiovascular diseases (CVDs) - Fact sheet [Internet]. WHO, 2017. Available: http:// www.who.int/mediacentre/factsheets/fs317/en/ [Accessed 22 Aug 2017].

43. GBD 2013 Mortality and Causes of Death Collaborators. Global, regional, and national age-sex specific all-cause and causespecific mortality for 240 causes of death, 1990-2013: a systematic analysis for the global burden of disease study 2013. The Lancet 2015;385:117-71.

44. Joseph P, Yusuf S, Lee SF, et al. Prognostic validation of a NonLaboratory and a laboratory based cardiovascular disease risk score in multiple regions of the world. Heart 2018;104:581-7.

45. Ueda P, Woodward M, Lu Y, et al. Laboratory-Based and office-based risk scores and charts to predict 10-year risk of cardiovascular disease in 182 countries: a pooled analysis of prospective cohorts and health surveys. Lancet Diabetes Endocrinol 2017;5:196-213

46. Gaziano TA, Young CR, Fitzmaurice G, et al. LaboratoryBased versus non-laboratory-based method for assessment of cardiovascular disease risk: the NHANES I follow-up study cohort. The Lancet 2008;371:923-31. 